\title{
The neutrophil-lymphocyte ratio and locoregional melanoma: a multicentre cohort study
}

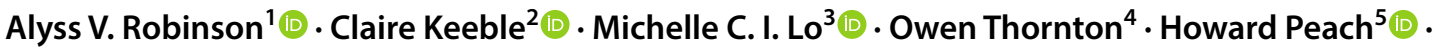 \\ Marc D. S. Moncrieff ${ }^{3,6}$. Donald J. Dewar ${ }^{5} \cdot$ Ryckie G. Wade $^{1,5}$
}

Received: 25 September 2019 / Accepted: 31 December 2019 / Published online: 23 January 2020

(c) The Author(s) 2020

\begin{abstract}
Objectives The neutrophil-lymphocyte ratio (NLR) is an inflammatory biomarker which is useful in cancer prognostication. We aimed to investigate the differences in baseline NLR between patients with localised and metastatic cutaneous melanoma and how this biomarker changed over time with the recurrence of disease.

Methods This multicentre cohort study describes patients treated for Stage I-III cutaneous melanoma over 10 years. The baseline NLR was measured immediately prior to surgery and again at the time of discharge or disease recurrence. The odds ratios (OR) for sentinel node involvement are estimated using mixed-effects logistic regression. The risk of recurrence is estimated using multivariable Cox regression.

Results Overall 1489 individuals were included. The mean baseline NLR was higher in patients with palpable nodal disease compared to those with microscopic nodal or localised disease (2.8 versus 2.4 and 2.3, respectively; $p<0.001$ ). A baseline NLR $\geq 2.3$ was associated with $30 \%$ higher odds of microscopic metastatic melanoma in the sentinel lymph node [adjusted OR 1.3 (95\% CI 1.3, 1.3)]. Following surgery, 253 patients $(18.7 \%)$ developed recurrent melanoma during surveillance although there was no statistically significant association between the baseline NLR and the risk of recurrence [adjusted HR $0.9(0.7,1.1)]$.

Conclusion The NLR is associated with the volume of melanoma at presentation and may predict occult sentinel lymph metastases. Further prospective work is required to investigate how NLR may be modelled against other clinicopathological variables to predict outcomes and to understand the temporal changes in NLR following surgery for melanoma.
\end{abstract}

Keywords Neutrophil-lymphocyte ratio $\cdot$ Platelet-lymphocyte ratio $\cdot$ Lymphocyte-monocyte ratio $\cdot$ Cutaneous melanoma Recurrence · Biomarker

$\begin{array}{ll}\text { Abbreviations } \\ \text { CI } & \text { Confidence interval } \\ \text { FBC } & \text { Full blood count } \\ \text { HR } & \text { Hazard ratio } \\ \text { IQR } & \text { Interquartile range }\end{array}$

Derivations of this work were presented at the triennial World Melanoma Congress (Brisbane, Australia; 2017); the Canadian Society of Surgical Oncology Annual Symposium (Vancouver Island, Canada; 2017 [56]); the British Association of Plastic, Reconstructive and Aesthetic Surgeons Winter Meeting (London, UK; 2017); the International Pigmented Cell Congress (Denver, USA; 2017); the European Association of Dermato-Oncology International Congress (Athens, 2017 [57]) and Melanoma FOCUS (Newcastle 2017, UK).

Ryckie G. Wade

ryckiewade@gmail.com

Extended author information available on the last page of the article
NLR Neutrophil lymphocyte ratio

OR Odds ratio

SLN Sentinel lymph node

WLE Wider local excision

\section{Introduction}

The incidence of melanoma has risen faster than any other cancer worldwide $[1,2]$ and the status of the sentinel lymph node (SLN) is the single most important prognostic factor [3]. Whilst there are several algorithms for predicting metastases of melanoma to the SLN [4-10] their external validity is weak [4,11-14]. Consequently, only 1 in 5 patients undergoing SLN biopsy yield a node with microscopic deposits [15]. SLN biopsy for melanoma carries an $11 \%$ risk of complication [16] and recent trials $[17,18]$ suggest no additional 
survival benefit from completion lymphadenectomy. Therefore, whilst staging the draining nodal basin remains an important goal, there is a pressing need to improve patient selection and avoid unnecessary SLN biopsies which might be achieved using host biomarkers [19].

For surgically resected BRAF V600-positive Stage III melanoma, adjuvant dabrafenib and trametinib improves survival, although discontinuation due to adverse effects is common (25\%) [20]. Further, adjuvant treatment for nonBRAF-mutated tumours improves survival but again, $15 \%$ experience drug-related adverse effects and rarely, premature-death [21]. Therefore, it may be desirable to refine the selection of patients for adjuvant therapy to those at the highest risk of recurrence.

With recent advances in adjuvant therapy [22] and a rising incidence, the number of patients living with melanoma has dramatically increased. In light of the findings of the Multicentre Selective Lymphadenectomy Trial (MSLT-II) trial [19] yet more patients will be subject to surveillance rather than up-front lymphadenectomy. Therefore, early detection of recurrent disease is desirable as systemic therapies are more efficacious in patients with a lower disease burden [23]. Hence, there is an unmet need for a cheap, simple and reliable biomarker to augment the selection of patients for SLN biopsy and adjuvant therapy, and to aid in the surveillance of patients with melanoma.

In response to malignancy and for reasons that are not yet fully elucidated, the host induces a myeloid immune response (manifesting as neutrophilia and thrombocytosis) whilst suppressing the adaptive immune (lymphoid) lineage; paradoxically, this favours tumour growth, angiogenesis, and regional and distant metastasis [24, 25]. This inflammatory response is manifested in the peripheral blood neutrophil-lymphocyte ratio (NLR) [26-29], which has become an established biomarker of systemic inflammation and various outcomes in numerous cancers [30-32]. Further, the NLR has a strong association with survival in melanoma [33-39]. Currently, there is a gap in the literature concerning the relationship between NLR and outcomes in locoregional melanoma, the most prevalent form of the disease, which formed the rationale for this study.

\section{Methods}

\section{Study design and patients}

This is a multicentre cohort study of patients with locoregional melanoma who underwent surgery with curative intent between 2006 and 2016 in Yorkshire and the East of England, UK. A secure electronic database was prospectively completed and retrospectively augmented with blood test data from the hospitals' electronic systems.

\section{Eligibility criteria}

We included patients with a biopsy-proven primary cutaneous melanoma who underwent surgery (wide excision and sentinel lymph node biopsy or lymphadenectomy). Patients were excluded if no full blood count (FBC) was recorded at baseline. Patients were also excluded for any of the following reasons which are known to affect the NLR: another concurrent malignancy, active infection, pregnancy, chronic inflammatory conditions, proliferative haematopoietic disorders, pharmacological immunosuppression, multiple or occult primary melanoma, recurrent melanoma, unidentifiable or unclassifiable tumours.

\section{Variables}

All histopathological features of the primary tumour were recorded and updated following wider re-excision. We used the FBC obtained after excision biopsy but before surgery with curative intent (i.e. WLE and SLN biopsy or lymphadenectomy) to compute the baseline NLR (absolute neutrophil $\div$ absolute lymphocyte count). The platelet-lymphocyte and lymphocyte-monocyte ratios (PLR and LMR, respectively) were calculated likewise. If there were multiple blood tests acquired in this period, we used the result closest to the definitive surgery. In a nested cohort, the last available FBC (up to 28 days prior to the diagnosis of recurrence or discharge) was used to calculate changes in blood counts and their ratios over time.

\section{Outcomes}

The primary outcome was the association between NLR and occult metastatic melanoma in the SLN, identified by histopathological assessment. Secondary outcomes included: (1) differences in the baseline NLR between localised, microscopic metastatic and macroscopic disease presentations; and (2) the changes in NLR for those who developed recurrent melanoma detected clinically, radiologically and/or by cellular techniques (histopathological assessment of a biopsy with immunohistochemistry or cytological assessment of fine needle aspirates). Patients disease-free at discharge or lost to follow-up were censored. The time to recurrence was calculated from the date of definitive surgery (SLN biopsy or lymphadenectomy) to the date of the multidisciplinary team diagnosis of recurrent melanoma. 


\section{Statistics}

There was no literature on which to base a power calculation, so this was hypothesis generating research. Data were analysed using Stata v15. Blood counts (and ratios) were skewed but lognormal, so are summarised by the geometric mean and compared using t-based methods. The threshold for NLR (2.3) was informed by previous work [34, 37-39] and selected based on the optimum Harrell $\mathrm{C}$-statistic and assessment of restricted cubic splines. The association between NLR and the odds ratio (OR) for SLN metastasis was estimated using multilevel (mixed-effects) logistic regression, with random-effects carrying by the hospital, i.e. cluster. The risk of recurrence (hazard ratios, HR) was estimated using multivariable Cox regression. All covariables were selected a priori as per our protocol [6, 40-49]. Models were internally validated by lossless non-parametric bootstrapping by resampling with replacement, with 1000 iterations [50]. Confidence intervals (CI) are generated to the $95 \%$ level. The family-wise error rate was revised down according to Šidák to $p<0.001$.

\section{Results}

After per-protocol exclusions, data were available for 1489 of 2438 eligible patients at baseline and a nested cohort of 235 individuals had repeated blood data for testing (Fig. 1).

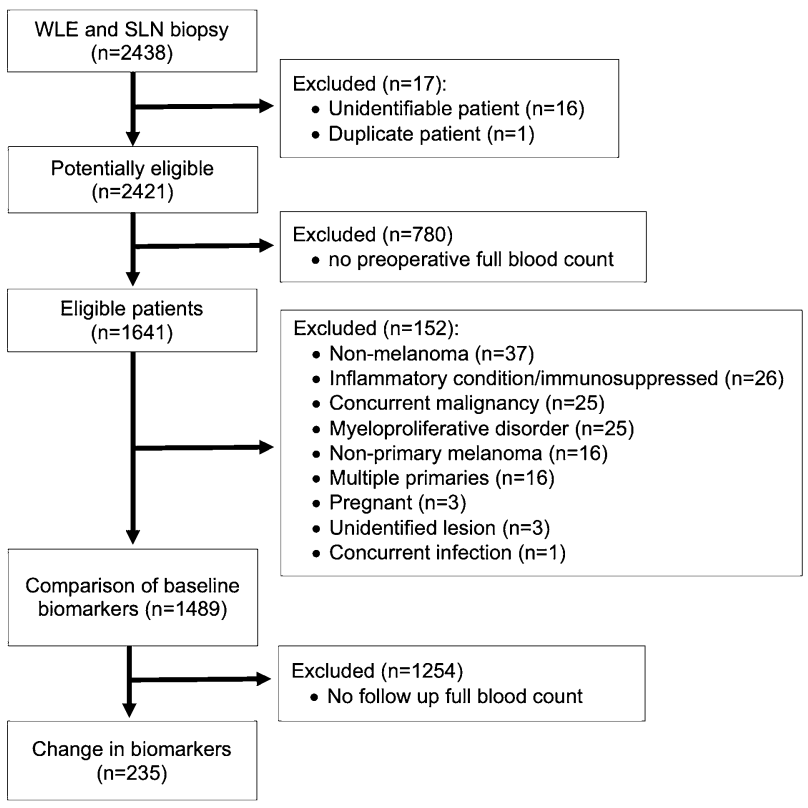

Fig. 1 Participant flow diagram

\section{Disease status at presentation}

Table 1 shows the baseline characteristics for those with localised melanoma (SLN biopsy negative), microscopic metastatic melanoma (SLN biopsy positive) and those who underwent therapeutic lymphadenectomy for palpable/macroscopic metastatic disease at presentation. There were no unexpected baseline differences between groups, except that our yield of positive SLN biopsies was higher than expected at $25 \%$.

\section{Peripheral blood biomarkers at presentation}

The median time from blood test to surgery (either SLN biopsy or therapeutic lymphadenectomy) was 19 days (IQR 3,28). Table 2 and Fig. 2 show that at presentation, the mean NLR was significantly higher in patients with palpable nodal disease [mean difference 0.2 (95\% CI 0.1, 0.3), $p<0.001$; Fig. 2] compared to others. The baseline NLR was also significantly higher in patients with microscopic metastatic melanoma in the SLN compared to those with a negative SLN biopsy, i.e. localised disease only [mean difference 0.1 (95\% CI 0.1, 0.2), $p=0.02$; Fig. 2].

Table 3 shows a strong univariable association between NLR and the risk of microscopic metastatic melanoma in the SLN. As a crude continuous predictor, the odds of metastatic disease in the SLN appeared to increase by $12 \%$ per unit rise in NLR [OR 1.2 (95\% CI 0.1, 1.2), $p=0.03$ ], compared to those with a localised disease. At a threshold of NLR $\geq 2.3$ there was a statistically significant association between a raised NLR and microscopic metastatic melanoma in the SLN, whereby a NLR $\geq 2.3$ increased the odds of metastasis by $30 \%$. Resampling did not change these estimates [bootstrapped adjusted OR 1.3 (95\% 1.2, 1.4), $p<0.001]$.

\section{Change in NLR over time}

The median follow-up was 3.6 years (IQR 2, 6 years; range 3 months to 10 years). During follow-up 253 patients (19\%) developed recurrent melanoma which included $16(13 \%)$ local recurrences, 44 (35\%) nodal recurrence and 66 (52\%) distant metastases; in the remaining cases the precise location of the recurrence was unclear.

Repeat (paired) blood data were available for a nested cohort of 235 individuals, all of whom had undergone SLN biopsy ( 80 positive, 155 negative). In this nested cohort, 86 (37\%) developed recurrence after a median of 50 months (IQR 26, 75). The remaining 149 individuals were disease-free at discharge after a median surveillance of 75 months (IQR 52,113). Table 2 shows no statistically significant difference in peripheral blood cell counts or their ratios, between those who developed recurrence and those who were disease-free at discharge. Further, in 
Table 1 Baseline characteristics comparing those disease-free (or censored) at final follow-up and those who developed recurrent melanoma

\begin{tabular}{|c|c|c|c|c|}
\hline & $\begin{array}{l}\text { Localised disease (SLN } \\
\text { negative, } n=1077 \text { ) }\end{array}$ & $\begin{array}{l}\text { Microscopic metastases } \\
\text { (SLN positive, } n=274 \text { ) }\end{array}$ & $\begin{array}{l}\text { Palpable disease (lym- } \\
\text { phadenectomy, } n=138 \text { ) }\end{array}$ & $p$ value \\
\hline Mean age in years (SD) & $63(13)$ & $60(14)$ & $65(17)$ & 0.004 \\
\hline \multicolumn{5}{|l|}{$\operatorname{Sex}(\%)$} \\
\hline Male & $542(50)$ & $136(50)$ & $70(51)$ & \multirow{2}{*}{0.9} \\
\hline Female & $535(50)$ & $138(50)$ & $68(49)$ & \\
\hline Median Breslow thickness (mm, IQR) & $1.8(1.2,3)$ & $2.2(1.5,3.5)$ & $2.5(1.4,4.5)$ & 0.001 \\
\hline Median Mitoses $\mathrm{mm}^{-2}$ (IQR) & $3(1,7)$ & $4(2,9)$ & $7(2,14)$ & 0.001 \\
\hline Median maximum diameter in mm (IQR) & $10(7,14)$ & $12(8,16)$ & $12(9,20)$ & 0.007 \\
\hline Ulceration $(\%)$ & $251(25)$ & $72(28)$ & $52(42)$ & $<0.001$ \\
\hline Angiolymphatic invasion (\%) & $14(3)$ & $19(12)$ & $16(20)$ & $<0.001$ \\
\hline Perineural invasion (\%) & $17(4)$ & $7(5)$ & $2(4)$ & 0.9 \\
\hline Regression (\%) & $71(17)$ & $22(14)$ & $19(23)$ & 0.2 \\
\hline Microsatellites (\%) & $15(4)$ & $14(9)$ & $14(25)$ & $<0.001$ \\
\hline \multicolumn{5}{|l|}{ Tumour-infiltrating lymphocytes (\%) } \\
\hline Absent & $59(14)$ & $33(22)$ & $20(24)$ & \multirow[t]{3}{*}{0.001} \\
\hline Non-brisk & $268(65)$ & $106(70)$ & $51(61)$ & \\
\hline Brisk & $86(21)$ & $12(8)$ & $12(15)$ & \\
\hline Vertical growth phase $(\%)$ & $382(96)$ & $142(99)$ & $70(100)$ & 0.04 \\
\hline \multicolumn{5}{|l|}{ Pathological subtype (\%) } \\
\hline Nodular & $98(9)$ & $26(10)$ & $39(28)$ & \multirow[t]{4}{*}{$\mathrm{n} / \mathrm{a}^{\mathrm{a}}$} \\
\hline Superficial spreading & $305(28)$ & $104(38)$ & $47(37)$ & \\
\hline Acral & $14(12)$ & $8(2)$ & $10(7)$ & \\
\hline Other & $660(61)$ & $136(50)$ & $42(25)$ & \\
\hline Residual melanoma in wider re-excision (\%) & $51(12)$ & $23(15)$ & $25(38)$ & $<0.001$ \\
\hline Extracapsular spread (\%) & $\mathrm{n} / \mathrm{a}$ & $16(12)$ & $66(48)$ & $<0.001$ \\
\hline \multicolumn{5}{|l|}{ Number of involved lymph nodes (\%) } \\
\hline 1 & $\mathrm{n} / \mathrm{a}$ & 81 & 93 & \multirow[t]{4}{*}{$\mathrm{n} / \mathrm{a}^{\mathrm{a}}$} \\
\hline 2 & & 21 & 66 & \\
\hline 3 & & 3 & 28 & \\
\hline$\geq 4$ & & 1 & 92 & \\
\hline
\end{tabular}

${ }^{\mathrm{a}}$ As we have arbitrarily grouped this data a test of proportion would not be informative

those who developed recurrence, there was no statistically significant change in peripheral blood cell counts or their ratios from baseline to the onset of recurrence.

\section{Baseline NLR and the risk of recurrence}

Table 4 shows that the NLR was not significantly associated with the risk of recurrence in either univariable [HR $1.1(95 \%$ CI 1.0, 1.2)] or multivariable [adjusted HR 0.9 (95\% CI 0.7, 1.1)] models, which is summarised by the Kaplan-Meier plot in Fig. 3. The only variable which predicted disease recurrence was SLN positivity which increased the risk of relapse fivefold. Re-sampling did not change these estimates.

\section{Discussion}

This study suggests that the neutrophil-lymphocyte ratio (NLR) is proportional to the volume of cutaneous melanoma at presentation. This finding supports the wider literature on other cancers which infers that the NLR represents the host response to malignancy and thus, is a reliable and personalised biomarker.

There are three published works concerning the NLR and lymph node metastases of melanoma [34, 37, 38], all of which agree with our findings that a raised NLR is associated with occult metastatic disease. Gandini et al. [34] compared absolute blood counts between SLN biopsy positive and negative individuals using rank-based 
Table 2 Blood values at disease presentation and final follow-up

\begin{tabular}{|c|c|c|c|c|c|c|c|c|}
\hline & \multicolumn{8}{|c|}{ Geometric means $(95 \% \mathrm{CI})$} \\
\hline & Leucocytes & Neutrophils & Lymphocytes & Monocytes & Platelets & $\begin{array}{l}\text { Neutrophil- } \\
\text { lymphocyte } \\
\text { ratio (NLR) }\end{array}$ & $\begin{array}{l}\text { Platelet-lym- } \\
\text { phocyte ratio } \\
\text { (PLR) }\end{array}$ & $\begin{array}{l}\text { Lymphocyte- } \\
\text { monocyte ratio } \\
\text { (LMR) }\end{array}$ \\
\hline \multicolumn{9}{|c|}{ Disease status at presentation } \\
\hline $\begin{array}{l}\text { Localised } \\
\text { (SLN nega- } \\
\text { tive) }\end{array}$ & $7.2(7.0,7.3)$ & $4.4(4.3,4.6$ & $1.9(1.8,1.9)$ & $0.4(0.4,0.4)$ & $252(246,258)$ & $2.3(1.8,3.1)$ & $132(130,140)$ & $4.6(4.5,4.8)$ \\
\hline $\begin{array}{l}\text { Microscopic } \\
\text { metastases } \\
\text { (SLN posi- } \\
\text { tive) }\end{array}$ & $7.3(6.9,7.7)$ & $4.6(4.3,4.8)$ & $1.8(1.7,1.9)$ & $0.4(0.4,0.5)$ & $249(239,259)$ & $2.4(1.8,3.3)$ & $137(129,146)$ & $4.3(4.0,4.6)$ \\
\hline $\begin{array}{l}\text { Palpable } \\
\text { disease } \\
\text { (lymphad- } \\
\text { enectomy) }\end{array}$ & $7.4(7.1,7.8)$ & $4.7(4.5,5.1)$ & $1.7,(1.6,1.8)$ & $0.4(0.4,0.4)$ & $255(244,266)$ & $2.8(2.0,3.7)$ & $153(142,165)$ & $4.0(3.7,4.4)$ \\
\hline$p$ value $^{\mathrm{a}}$ & 0.4 & 0.09 & 0.003 & 0.3 & 0.7 & $<0.001$ & 0.003 & 0.001 \\
\hline \multicolumn{9}{|c|}{ Disease status at final follow-up } \\
\hline $\begin{array}{l}\text { Disease free } \\
\text { (discharged) }\end{array}$ & $7.1(6.7,7.6)$ & $4.2(4.0,4.5)$ & $1.8(1.7,1.9)$ & $0.4(0.4,0.4)$ & $243(234,253)$ & $2.4(2.2,2.6)$ & $138(130,146)$ & $4.5(4.2,4.8)$ \\
\hline $\begin{array}{l}\text { Recurrent } \\
\text { melanoma }\end{array}$ & $6.8(6.4,7.3)$ & $4.1(3.8,4.5)$ & $1.7(1.6,1.9)$ & $0.4(0.4,0.4)$ & $241(227,256)$ & $2.4(2.1,2.6)$ & $139(127,151)$ & $4.3(3.9,4.7)$ \\
\hline$p$ value $^{\mathrm{a}}$ & 0.4 & 0.5 & 0.8 & 0.5 & 0.8 & 0.9 & 0.9 & 0.4 \\
\hline
\end{tabular}

SLN sentinel lymph node

${ }^{\text {a } D e r i v e d ~ f r o m ~ l i n e a r ~ r e g r e s s i o n ~ o f ~ l o g n o r m a l ~ d a t a ~}$

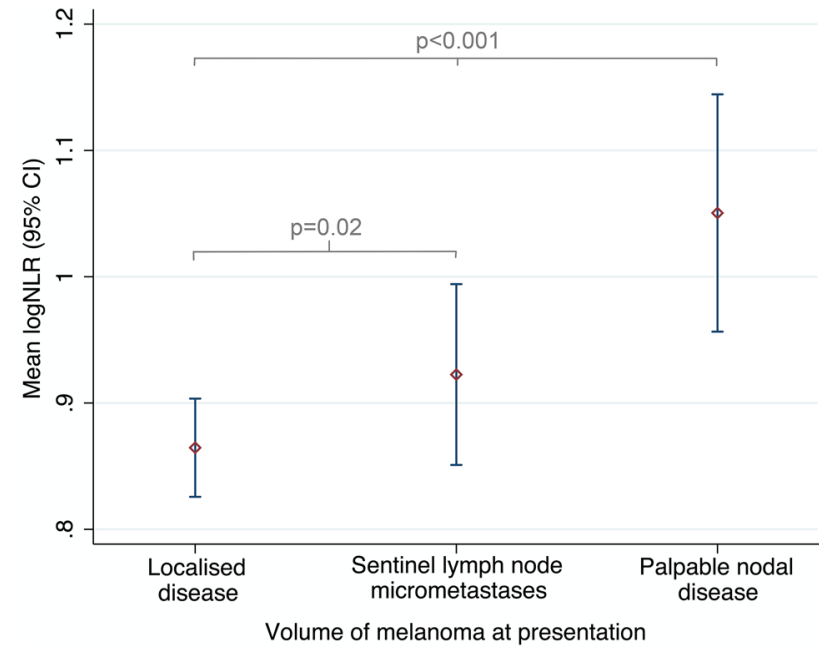

Fig. 2 The mean $\operatorname{logNLR}(95 \%$ CI) for each group, based on disease volume at presentation. Groups were compared by ANOVA with Bonferroni correction. The logNLR is the natural logarithm of the NLR

methods and found no evidence of a difference; but when modelled against disease progression using Cox regression (from Stage I/II to III, i.e. when melanoma metastasises), a raised NLR was strongly predictive. This agrees with our data whereby the crude blood counts were not different between groups and highlights the power of ratios which magnify smaller differences to appreciable levels.

Lino-Silva and colleagues [38] showed that a NLR $>2$ was associated with nodal metastasis; however, their study concerned acral lentiginous melanoma in the Mexican population which is a biologically distinct tumour and population, respectively. This reduces the generalisability to the majority of affected individuals who are Caucasian with nodular or superficial spreading melanoma [51]. The proportional analysis by Davis et al. [37] showed that the baseline NLR was higher in patients with a more advanced nodal substage and thicker tumours. However, they found no significant difference in the NLR between patients with macroscopic and microscopic metastatic melanoma [37]. Overall, our findings agree with the literature and suggest that a raised baseline NLR is associated with occult metastatic melanoma. Previous works investigated NLR incidentally or as a secondary outcome of interest [34, 37,38 ] whereas this study adds an important dimension to the literature because the biomarker was of primary interest, analysed in a comprehensive fashion and adjusted for potential confounding variables. None-the-less, we feel that further prospective research is needed to mitigate biases of selection and information before the NLR is utilised in the management of patients with locoregional melanoma. 
Table 3 Odds of occult sentinel lymph node metastasis

\begin{tabular}{|c|c|c|c|c|}
\hline & $\begin{array}{l}\text { Univariable OR } \\
(95 \% \text { CI })\end{array}$ & $p$ value & Adjusted $^{\mathrm{a}}$ OR $(95 \% \mathrm{CI})$ & $p$ value \\
\hline $\mathrm{NLR} \geq 2.3$ & $1.2(0.9,1.6)$ & 0.3 & $1.3(1.3,1.3)$ & $<0.001$ \\
\hline Angiolymphatic invasion & $4.1(2.0,8.4)$ & $<0.001$ & $3.5(1.9,6.2)$ & $<0.001$ \\
\hline Microsatellites & $2.8(1.3,5.9)$ & 0.008 & $1.7(1.4,2.0)$ & $<0.001$ \\
\hline Mitoses per $\mathrm{mm}^{2}$ & $1.0(1.0,1.1)$ & 0.001 & $1.1(1.1,1.1)$ & $<0.001$ \\
\hline Breslow thickness (mm) & $1.1(1.1,1.2)$ & $<0.001$ & $1.1(1.1,1.2)$ & $<0.001$ \\
\hline Age in years & $1.0(1.0,1.0)$ & 0.010 & $1.0(1.0,1.0)$ & $<0.001$ \\
\hline Male & $1.0(0.8,1.3)$ & 0.9 & $1.1(0.8,1.5)$ & 0.7 \\
\hline Ulceration & $1.2(0.9,1.6)$ & 0.4 & $1.1(0.8,1.5)$ & 0.8 \\
\hline Regression & $0.8(0.5,1.4)$ & 0.5 & $0.9(0.7,1.2)$ & 0.5 \\
\hline \multicolumn{5}{|l|}{ Anatomical location } \\
\hline Head and neck & 1 (referent) & 0.002 & 1 (referent) & 0.01 \\
\hline Upper limb & $1.5(0.9,2.7)$ & & $1.5(0.6,3.5)$ & \\
\hline Lower limb & $2.3(2.3,4.0)$ & & $1.8(0.9,3.6)$ & \\
\hline Trunk and genitals & $2.4(0.9,2.7)$ & & $2.5(1.2,5.0)$ & \\
\hline \multicolumn{5}{|l|}{ TILs } \\
\hline Absent & 1 (referent) & $<0.001$ & 1 (referent) & $<0.001$ \\
\hline Non-brisk & $0.7(0.4,1.1)$ & & $0.6(0.6,0.6)$ & \\
\hline Brisk & $0.2(0.1,0.5)$ & & $0.2(0.2,0.3)$ & \\
\hline
\end{tabular}

CI confidence interval, $O R$ odds ratio, TILs tumour-infiltrating lymphocytes

${ }^{a}$ Mixed-effects logistic regression with random-effects varying by the hospital cluster

\begin{tabular}{|c|c|c|c|c|}
\hline & \multicolumn{2}{|c|}{ Unadjusted risk } & \multicolumn{2}{|l|}{ Adjusted $^{\mathrm{a}}$ risk } \\
\hline & $\mathrm{HR}(95 \% \mathrm{CI})$ & $p$ value & HR $(95 \%$ CI $)$ & $p$ value \\
\hline \multicolumn{5}{|l|}{ Host factors } \\
\hline Neutrophil-lymphocyte ratio & $1.1(1.0,1.2)$ & 0.2 & $0.9(0.7,1.1)$ & 0.2 \\
\hline Age & $1.0(1.0,1.0)$ & 0.008 & $1.0(1.0,1.0)$ & 0.01 \\
\hline \multicolumn{5}{|l|}{ Primary tumour factors } \\
\hline Breslow thickness & $1.1(1.1,1.2)$ & $<0.001$ & $1.1(1.0,1.3)$ & 0.009 \\
\hline Ulceration & $1.5(1.1,2.0)$ & 0.003 & $1.1(0.6,2.0)$ & 0.9 \\
\hline Mitoses per $\mathrm{mm}^{2}$ & $1.0(1.0,1.1)$ & $<0.001$ & $1.0(1.0,1.0)$ & 0.1 \\
\hline Angiolymphatic invasion & $3.4(2.1,5.5)$ & $<0.001$ & $1.4(0.7,2.9)$ & 0.4 \\
\hline Microsatellites & $2.5(1.4,4.2)$ & 0.001 & $1.8(0.4,4.0)$ & 0.2 \\
\hline Absence of tumour-infiltrating lymphocytes & $4.9(2.3,11)$ & $<0.001$ & $5.6(1.6,19)$ & 0.008 \\
\hline \multicolumn{5}{|l|}{ Location } \\
\hline Trunk and genitals & 1 (referent) & $<0.001$ & 1 (referent) & 0.001 \\
\hline Upper limb & $0.7(0.5,1.0)$ & & $0.5(0.3,0.9)$ & \\
\hline Lower limb & $1.4(1.1,1.9)$ & & $1.0(0.6,1.8)$ & \\
\hline Head and neck & $1.4(1.0,2.1)$ & & $2.4(1.3,4.5)$ & \\
\hline \multicolumn{5}{|l|}{ Regional node factors } \\
\hline Sentinel lymph node metastasis & $5.8(4.5,7.3)$ & $<0.001$ & $5.7(3.8,8.5)$ & $<0.001$ \\
\hline Extracapsular spread & $1.0(0.5,2.0)$ & 0.9 & - & - \\
\hline
\end{tabular}

$H R$ hazard ratio, $C I$ confidence interval

${ }^{a}$ Multivariable Cox regression with age, Breslow thickness, mitotic rate and NLR modelled as continuous variables, whilst other co-variables were handled as categorical variables
There is a wealth of data on haematological biomarkers in metastatic melanoma, which show that a raised baseline
NLR is associated with almost twice the risk of recurrence following systemic therapy [HR 1.86 (95\% CI 1.2, 2.8)] [52]; 




Fig. 3 A Kaplan-Meier plot showing the development of recurrence according to the baseline NLR. The $p$ value is derived from the logrank test

however, the literature is comparatively sparse in locoregional melanoma [34, 37-39]. Of these studies, Lino-Silva [38] is the only one to report the association between baseline NLR and the risk of recurrence. They stated that in 376 patients a baseline NLR $\geq 2$ was associated with a higher risk of recurrence ( $28 \%$ versus $22 \%$ ), although the limitations of their sample have already been discussed. Also, this apparent proportional difference was not subject to a hypothesis test (and so no effect size was offered), nor was it adjusted for important baseline confounders. These factors might explain why it differs to our finding. We add data to this important deficit in the literature concerning biomarkers in locoregional melanoma and suggest that future researchers seek to evaluate the utility of the baseline NLR in a prospective cohort of individuals with locoregional melanoma, with regular repeated measurements (including immediately after surgery) to better understand the temporal change of this valuable biomarker in melanoma.

The translational value of the NLR in the care of patients with melanoma is potentially important because the association between NLR and survival from metastatic melanoma is unequivocal [52]. The systematic review and meta-regression by Ding et al. [53] (using data from 12 studies and 3207 individuals with melanoma) showed that the NLR was strongly predictive of overall survival [HR 2.2 (95\% CI 1.6, 3.0)] and disease-free survival [HR 2.2 (95\% CI 1.8, 2.7)]. Recent data from our group complements this review and showed that the baseline NLR was a potentially powerful adjunct to SLN biopsy for identifying those individuals at the highest risk of death [39] who might benefit most from adjuvant therapy. Therefore, as SLN status is the best predictor of survival in melanoma, and survival is strongly associated with the NLR, our findings and those of prior studies
$[34,37,38]$ suggest that NLR might help to better inform treatment choices for patients in the future [19].

\section{Limitations}

The retrospective nature of the study meant many of the patients did not have a blood test during surveillance, hence our nested cohort was only 235 patients and may have been underpowered to detect a significant difference in NLR. The median follow-up for recurrence was only 3.6 years, which would capture over $80 \%$ of disease recurrences [54] but may not identify up to $11 \%$ of late melanoma recurrences [55]. We quantified change in biomarkers by comparing the pre-operative values to the final value; however, it is possible that the NLR may normalise following surgery and therefore affect our findings, i.e. if the NLR was abnormal preoperatively but regressed to normal following surgery, before again rising with recurrence. Our study was subject to missing data but the missingness was completely at random, so unlikely to bias the outcomes. Future work could measure postoperative NLR in addition to pre-operative levels, to understand the temporal changes following surgery.

\section{Conclusion}

The baseline NLR is associated with the volume of cutaneous melanoma at presentation. Further prospective research is needed to understand how this personalised biomarker changes following surgery for melanoma and whether it may also be used for surveillance.

Author contributions The study was conceived by RGW and HP. HP, DJD and MDSM treated patients. AVR, MCIL, OT, HP, DJD, MDSM and RGW collected data. RGW and CK analysed the data. AVR and RGW drafted the manuscript. All authors edited and approved the final manuscript.

Funding Ryckie Wade is a Doctoral Research Fellow funded by the National Institute for Health Research (NIHR, DRF-2018-11-ST2-028) and the research is supported by the NIHR infrastructure at Leeds. The views expressed are those of the author(s) and not necessarily those of the NHS, the NIHR or the Department of Health.

\section{Compliance with ethical standards}

Conflict of interest The authors declare that they have no conflicts of interest.

Ethical approval Approval was gained from the Research and Ethical Committees of Leeds Teaching Hospitals (reference PL15/368) and the National Health Research Authority for Norwich (IRAS project ID: 234565). This study was conducted in accordance with the Declaration of Helsinki. 
Informed consent We did not seek consent from patients to use their data in this study because this was not necessary as this was not defined as research and no new data were gathered, as determined by local ethical committee and institutional research department reviews.

Open Access This article is licensed under a Creative Commons Attribution 4.0 International License, which permits use, sharing, adaptation, distribution and reproduction in any medium or format, as long as you give appropriate credit to the original author(s) and the source, provide a link to the Creative Commons licence, and indicate if changes were made. The images or other third party material in this article are included in the article's Creative Commons licence, unless indicated otherwise in a credit line to the material. If material is not included in the article's Creative Commons licence and your intended use is not permitted by statutory regulation or exceeds the permitted use, you will need to obtain permission directly from the copyright holder. To view a copy of this licence, visit http://creativecommons.org/licenses/by/4.0/.

\section{References}

1. You W, Henneberg M (2018) Cancer incidence increasing globally: the role of relaxed natural selection. Evol Appl. https://doi. org/10.1111/eva.12523

2. Stewart B, Wild (2014) International Agency for Research on Cancer. World Cancer Report 2014. World Health Organisation. https://publications.iarc.fr/Non-Series-Publications/World-Cance r-Reports/World-Cancer-Report-2014

3. Balch CM, Soong S-J, Gershenwald JE et al (2001) Prognostic factors analysis of 17,600 melanoma patients: validation of the American Joint Committee on Cancer Melanoma Staging System. J Clin Oncol 19:3622-3634. https://doi.org/10.1200/ JCO.2001.19.16.3622

4. Wong SL, Kattan MW, McMasters KM, Coit DG (2005) A nomogram that predicts the presence of sentinel node metastasis in melanoma with better discrimination than the American Joint Committee on CancerStaging System. Ann Surg Oncol 12:282288. https://doi.org/10.1245/ASO.2005.05.016

5. Mocellin S, Thompson JF, Pasquali S et al (2009) Sentinel node status prediction by four statistical models: results from a large bi-institutional series $(n=1132)$. Ann Surg 250:964-969

6. Mitra A, Conway C, Walker C et al (2010) Melanoma sentinel node biopsy and prediction models for relapse and overall survival. Br J Cancer 103:1229-1236. https://doi.org/10.1038/ sj.bjc.6605849

7. Kruper LL, Spitz FR, Czerniecki BJ et al (2006) Predicting sentinel node status in AJCC stage I/II primary cutaneous melanoma. Cancer 107:2436-2445. https://doi.org/10.1002/cncr.22295

8. Karakousis GC, Gimotty PA, Botbyl JD et al (2006) Predictors of regional nodal disease in patients with thin melanomas. Ann Surg Oncol 13:533-541. https://doi.org/10.1245/ASO.2006.05.011

9. Sondak VK, Taylor JMG, Sabel MS et al (2004) Mitotic rate and younger age are predictors of sentinel lymph node positivity: lessons learned from the generation of a probabilistic model. Ann Surg Oncol 11:247-258. https://doi.org/10.1245/ ASO.2004.03.044

10. Paek SC, Griffith KA, Johnson TM et al (2007) The impact of factors beyond Breslow depth on predicting sentinel lymph node positivity in melanoma. Cancer 109:100-108. https://doi. org/10.1002/cncr.22382

11. Pasquali S, Mocellin S, Campana LG et al (2011) Maximizing the clinical usefulness of a nomogram to select patients candidate to sentinel node biopsy for cutaneous melanoma. Eur J Surg Oncol 37:675-680. https://doi.org/10.1016/j.ejso.2011.05.007

12. Piñero A, Canteras M, Ortiz E et al (2008) Validation of a nomogram to predict the presence of sentinel lymph node metastases in melanoma. Ann Surg Oncol 15:2874-2877. https://doi. org/10.1245/s10434-008-0077-x

13. Woods JFC, De Marchi JA, Lowery AJ, Hill ADK (2015) Validation of a nomogram predicting sentinel lymph node status in melanoma in an Irish population. Ir J Med Sci (1971-) 184:769-773. https://doi.org/10.1007/s11845-014-1166-4

14. Sabel MS, Rice JD, Griffith KA et al (2012) Validation of statistical predictive models meant to select melanoma patients for sentinel lymph node biopsy. Ann Surg Oncol 19:287-293. https ://doi.org/10.1245/s10434-011-1979-6

15. Morton DL, Thompson JF, Cochran AJ et al (2014) Final trial report of sentinel-node biopsy versus nodal observation in melanoma. N Engl J Med 370:599-609. https://doi.org/10.1056/ NEJMoa1310460

16. Moody JA, Ali RF, Carbone AC et al (2017) Complications of sentinel lymph node biopsy for melanoma-a systematic review of the literature. Eur J Surg Oncol 43:270-277. https:// doi.org/10.1016/j.ejso.2016.06.407

17. Leiter U, Stadler R, Mauch C et al (2016) Complete lymph node dissection versus no dissection in patients with sentinel lymph node biopsy positive melanoma (DeCOG-SLT): a multicentre, randomised, phase 3 trial. Lancet Oncol 17:757-767. https:// doi.org/10.1016/S1470-2045(16)00141-8

18. Faries MB, Cochran AJ, Elashoff RM, Thompson JF (2015) Multicenter selective lymphadenectomy trial-I confirms the central role of sentinel node biopsy in contemporary melanoma management. Br J Dermatol 172:571-573. https://doi. org/10.1111/bjd.13676

19. Faries MB (2018) Completing the dissection in melanoma: increasing decision precision. Ann Surg Oncol. https://doi. org/10.1245/s10434-017-6330-4

20. Long GV, Hauschild A, Santinami M et al (2017) Adjuvant dabrafenib plus trametinib in stage III BRAF-mutated melanoma. N Engl J Med 377:1813-1823. https://doi.org/10.1056/NEJMoa1708 539

21. Eggermont AMM, Blank CU, Mandala M et al (2018) Adjuvant pembrolizumab versus placebo in resected stage III melanoma. N Engl J Med 378:1789-1801. https://doi.org/10.1056/NEJMoa1802 357

22. National Institute for Health and Care Excellence (2018) Dabrafenib with trametinib for adjuvant treatment of resected BRAF V600 mutation-positive melanoma

23. Long GV, Grob JJ, Nathan P et al (2016) Factors predictive of response, disease progression, and overall survival after dabrafenib and trametinib combination treatment: a pooled analysis of individual patient data from randomised trials. Lancet Oncol 17:1743-1754. https://doi.org/10.1016/S1470-2045(16)30578-2

24. Wu X, Tomonori T, Sullivan A, Hwang ST (2011) Inflammation and tumour microenvironment in lymph node metastasis. Cancers (Basel) 3:927-944. https://doi.org/10.3390/cancers3010927

25. Nathanson SD (2003) Insights into the mechanisms of lymph node metastasis. Cancer 98:413-423. https://doi.org/10.1002/ cncr.11464

26. Coffelt SB, Wellenstein MD, de Visser KE (2016) Neutrophils in cancer: neutral no more. Nat Rev Cancer 16:431-446. https://doi. org/10.1038/nrc. 2016.52

27. Richards DM, Hettinger J, Feuerer M (2013) Monocytes and macrophages in cancer: development and functions. Cancer Microenviron 6:179-191. https://doi.org/10.1007/s12307-012-0123-x

28. Gay LJ, Felding-Habermann B (2011) Contribution of platelets to tumour metastasis. Nat Rev Cancer 11:123-134. https://doi. org/10.1038/nrc3004 
29. Ray-Coquard I, Cropet C, Van Glabbeke M et al (2009) Lymphopenia as a prognostic factor for overall survival in advanced carcinomas, sarcomas, and lymphomas. Cancer Res 69:5383-5391. https://doi.org/10.1158/0008-5472.CAN-08-3845

30. Templeton AJ, McNamara MG, Eruga B et al (2014) Prognostic role of neutrophil-to-lymphocyte ratio in solid tumors: a systematic review and meta-analysis. JNCI J Natl Cancer Inst 106:124. https://doi.org/10.1093/jnci/dju124

31. Templeton AJ, Ace O, McNamara MG et al (2014) Prognostic role of platelet to lymphocyte ratio in solid tumors: a systematic review and meta-analysis. Cancer Epidemiol Biomark Prev 23:1204-1212. https://doi.org/10.1158/1055-9965.EPI-14-0146

32. Nishijima TF, Muss HB, Shachar SS et al (2015) Prognostic value of lymphocyte-to-monocyte ratio in patients with solid tumors: a systematic review and meta-analysis. Cancer Treat Rev 41:971978. https://doi.org/10.1016/j.ctrv.2015.10.003

33. Ma J, Kuzman J, Ray A et al (2018) Neutrophil-to-lymphocyte ratio (NLR) as a predictor for recurrence in patients with stage III melanoma. Sci Rep. https://doi.org/10.1038/s41598-018-22425-3

34. Gandini S, Ferrucci PF, Botteri E et al (2016) Prognostic significance of hematological profiles in melanoma patients. Int J Cancer 139:1618-1625. https://doi.org/10.1002/ijc.30215

35. Ferrucci PF, Ascierto PA, Pigozzo J et al (2016) Baseline neutrophils and derived neutrophil-to-lymphocyte ratio: prognostic relevance in metastatic melanoma patients receiving ipilimumab. Ann Oncol 27:732-738. https://doi.org/10.1093/annonc/mdw016

36. Ferrucci PF, Gandini S, Battaglia A et al (2015) Baseline neutrophil-to-lymphocyte ratio is associated with outcome of ipilimumab-treated metastatic melanoma patients. Br J Cancer 112:1904-1910. https://doi.org/10.1038/bjc.2015.180

37. Davis JL, Langan RC, Panageas KS et al (2017) Elevated blood neutrophil-to-lymphocyte ratio: a readily available biomarker associated with death due to disease in high risk nonmetastatic melanoma. Ann Surg Oncol 24:1989-1996. https://doi. org/10.1245/s10434-017-5836-0

38. Lino-Silva LS, Salcedo-Hernández RA, García-Pérez L et al (2017) Basal neutrophil-to-lymphocyte ratio is associated with overall survival in melanoma. Melanoma Res 27:140-144. https ://doi.org/10.1097/CMR.0000000000000333

39. Wade RG, Robinson AV, Lo MCI et al (2018) Baseline neutrophil-lymphocyte and platelet-lymphocyte ratios as biomarkers of survival in cutaneous melanoma: a multicenter cohort study. Ann Surg Oncol 25:3341-3349. https://doi.org/10.1245/s1043 4-018-6660-x

40. Pearce N (2016) Analysis of matched case-control studies. BMJ 148:i969. https://doi.org/10.1136/bmj.i969

41. Lyth J, Falk M, Maroti M et al (2017) Prognostic risk factors of first recurrence in patients with primary stages I-II cutaneous malignant melanoma-from the population-based Swedish melanoma register. J Eur Acad Dermatol Venereol 31:1468-1474. https ://doi.org/10.1111/jdv.14280

42. Statius Muller MG, van Leeuwen PAM, de Lange-de Klerk ESM et al (2001) The sentinel lymph node status is an important factor for predicting clinical outcome in patients with stage I or II cutaneous melanoma. Cancer 91:2401-2408

43. Van Es SL, Colman M, Thompson JF et al (2008) Angiotropism is an independent predictor of local recurrence and in-transit metastasis in primary cutaneous melanoma. Am J Surg Pathol 32:1396-1403. https://doi.org/10.1097/PAS.0b013e3181753a8e
44. Pawlik TM, Ross MI, Johnson MM et al (2005) Predictors and natural history of in-transit melanoma after sentinel lymphadenectomy. Ann Surg Oncol 12:587-596. https://doi.org/10.1245/ ASO.2005.05.025

45. Faut M, Wevers KP, van Ginkel RJ et al (2017) Nodular histologic subtype and ulceration are tumor factors associated with high risk of recurrence in sentinel node-negative melanoma patients. Ann Surg Oncol 24:142-149. https://doi.org/10.1245/ s10434-016-5566-8

46. Messeguer F, Agusti A, Guillen C et al (2011) Prognosis and risk factors of local recurrence in cutaneous melanoma. J Am Acad Dermatol 64:AB10. https://doi.org/10.1016/J.JAAD.2010.09.063

47. Stucky C-CH, Gray RJ, Dueck AC et al (2010) Risk factors associated with local and in-transit recurrence of cutaneous melanoma. Am J Surg 200:770-775. https://doi.org/10.1016/J.AMJSU RG.2010.07.025

48. Carlson GW, Page AJ, Cohen C et al (2008) Regional recurrence after negative sentinel lymph node biopsy for melanoma. Ann Surg 248:378-386. https://doi.org/10.1097/SLA.0b013e3181 855718

49. Crookes TR, Scolyer RA, Lo S et al (2017) Extranodal spread is associated with recurrence and poor survival in stage III cutaneous melanoma patients. Ann Surg Oncol 24:1378-1385. https:// doi.org/10.1245/s10434-016-5723-0

50. Collins GS, Reitsma JB, Altman DG, Moons KGM (2015) Transparent reporting of a multivariable prediction model for individual prognosis or diagnosis (TRIPOD): the TRIPOD statement. Eur Urol 67:1142-1151. https://doi.org/10.1016/j.eururo.2014.11.025

51. Schadendorf D, van Akkooi ACJ, Berking C et al (2018) Melanoma. Lancet 392:971-984. https://doi.org/10.1016/S0140 -6736(18)31559-9

52. Zhan H, Ma J-Y, Jian Q-C (2018) Prognostic significance of pretreatment neutrophil-to-lymphocyte ratio in melanoma patients: a meta-analysis. Clin Chim Acta 484:136-140

53. Ding Y, Zhang S, Qiao J (2018) Prognostic value of neutrophil-tolymphocyte ratio in melanoma. Medicine (Baltimore) 97:e11446. https://doi.org/10.1097/MD.0000000000011446

54. Fusi S, Ariyan S, Sternlicht A (1993) Data on first recurrence after treatment for malignant melanoma in a large patient population. Plast Reconstr Surg 91:94-98

55. Faries MB, Steen S, Ye X et al (2013) Late recurrence in melanoma: clinical implications of lost dormancy. J Am Coll Surg 217:27-34. https://doi.org/10.1016/j.jamcollsurg.2013.03.007

56. Wade R, Robinson A, Keeble C et al (2017) Baseline neutrophillymphocyte and platelet-lymphocyte ratios are associated with survival in cutaneous malignant melanoma; abstract no 10 in the 2017 Canadian Surgery Forum Abstracts. Can J Surg 60:S109S181. https://doi.org/10.1503/cjs.010417

57. Robinson A, Keeble C, Marples M et al (2017) Baseline neutrophil-lymphocyte, platelet-lymphocyte and lymphocyte-monocyte ratios do not predict survival in cutaneous malignant melanoma; abstract no. FC4.4. J Eur Acad Dermatol Venereol 31:3-100. https ://doi.org/10.1111/jdv.05_14275

Publisher's Note Springer Nature remains neutral with regard to jurisdictional claims in published maps and institutional affiliations. 


\section{Affiliations}

Alyss V. Robinson ${ }^{1}(1)$. Claire Keeble ${ }^{2}(1) \cdot$ Michelle C. I. Lo $^{3}\left(\mathbb{D} \cdot\right.$ Owen Thornton $^{4} \cdot$ Howard Peach $^{5}(\mathbb{D})$ Marc D. S. Moncrieff ${ }^{3,6}$ - Donald J. Dewar ${ }^{5} \cdot$ Ryckie G. Wade $^{1,5}$

1 Leeds Institute for Medical Research, University of Leeds, Leeds, UK

2 Leeds Institute for Data Analytics, University of Leeds, Leeds, UK

3 Plastic and Reconstructive Surgery Department, Norfolk and Norwich University Hospital NHS Trust, Norwich, UK
4 Trinity College Dublin, The University of Dublin, Dublin, Ireland

5 Department of Plastic and Reconstructive Surgery, Leeds General Infirmary, Leeds, UK

6 Norwich Medical School, University of East Anglia, Norwich, UK 